\title{
The Effect of Plaque Removal on Pressure Drop and Flow Rate through an Idealized Stenotic Lesion
}

\author{
Brian D. Plourde ${ }^{1}$, Lauren J. Vallez ${ }^{1}$, Biyuan Sun ${ }^{1}$, John P. Abraham ${ }^{1 *}$ and Cezar S. Staniloe ${ }^{2}$ \\ ${ }^{1}$ University of St. Thomas, School of Engineering, 2115 Summit Ave, St. Paul and Minneapolis, Minnesota 55105-1079, United States \\ ${ }^{2}$ NYU Langone Medical Center, 333 East 38th St, New York 10016, United States
}

"Corresponding author: John P. Abraham, University of St. Thomas, School of Engineering, 2115 Summit Ave, St. Paul and Minneapolis, Minnesota 55105-1079, United States, Tel: 651-962-5766; E-mail: jpabraham@stthomas.edu

Received date: December 7, 2015; Accepted date: December 15, 2015; Published date: December 21, 2015

Copyright: (c) 2015 Plourde, et al. This is an open-access article distributed under the terms of the Creative Commons Attribution License, which permits unrestricted use, distribution and reproduction in any medium, provided the original author and source are credited.

\begin{abstract}
Numerical calculations have been performed to quantify the importance of plaque removal on blood flow. The artery under consideration is the popliteal artery which is susceptible to plaque lesions. An orbital artherectomy device was used to partially remove a calcified plaque layer. Measurements taken before and after the treatment were used in idealized calculations and pressure losses through the lesion were determined.
\end{abstract}

It was found that the removal of plaque by orbital atherectomy increases the blood flowrate through the artery. At the same time, there is a major reduction of pressure loss through the lesion. After treatment, the systolic pressure drop was 2.5 times less than prior to treatment. The cycle-averaged pressure drop was improved by a factor of 3.5.

The results are similar for a wide range of plaque lesion lengths (from $3 \mathrm{~mm}$ to $18 \mathrm{~mm}$ ). A deeper investigation into the source of pressure loss reveals that the majority of the loss is confined to the entrance of the lesion and is caused by flow acceleration (and later deceleration) rather than by friction.

The calculations were repeated with three increasingly complex numerical methods (steady laminar, unsteady laminar, and unsteady transitional). It was found that all methods were in good agreement so that more computationally expensive techniques are not required in order to obtain accurate results.

The results of the simulation were compared with clinical pressure measurements before and after treatment. The two results were found to be in good agreement.

Keywords: Cardiovascular disease; Plaque; Blood flow; Stenosis; Computational fluid dynamics

\section{Introduction}

Cardiovascular disease is a major health risk throughout the world and the leading cause of death in some developed countries. Aside from risks to the coronary system, peripheral arteries can be compromised by plaque buildup. The topic of blood flow through arteries and the impact of the flow on the health of living organisms has been dealt with extensively in the literature and for brevity, review articles are referenced here for interested readers [1-4]. Prior research has included both numerical and clinical/experimental information. Research has progressed from steady flow in circular geometries [5-7]; flow through patient-specific arteries created from medical images $[8,9]$; unsteady flow driven by fluctuating pressure waveforms [10] with both Newtonian and non-Newtonian constitutive models for blood viscosity [11-13].

Aside from the relation of pressure to flow through arteries, the constitution of the wall has a significant impact on mass transport through the tissue [14-21]. Furthermore, the presence or absence of plaque has an impact on the compliant response of the arterial wall which, in turn, affects the blood flow. In the recent literature, studies have been completed to quantify this two-way interaction [22-42].
In the present study, a new question will be addressed related to the impact of plaque removal on the flow/pressure relationship. In particular, calcified plaque will be removed using a technique called orbital atherectomy [43-45]. The device is designed to be used either as a stand-alone procedure or more commonly in conjunction with balloon angioplasty. The preferential target is calcified plaque in the peripheral arteries for the treatment of peripheral arterial disease.

The device used for the procedure was the Diamondback 360 Peripheral Orbital Atherectomy System (OAS; Cardiovascular Systems, Inc.). The device is designed to remove calcified plaque while preserving the compliant tissue. For more information on the procedure, readers are invited to [41]. For the present study, the pretreated lesion had a minimum diameter of $3.39 \mathrm{~mm}$ and the post treated lesion opening was $5.05 \mathrm{~mm}$ measured by intravascular ultrasound. These measurements were incorporated into an idealized stenotic geometry to be discussed shortly.

In this particular case, standard lower extremity angiography of the entire vascular tree was performed. The Combo Wire ${ }^{\infty}$ (Volcano Corporation) was normalized at the level of the common femoral artery, and then placed in the distal popliteal artery, just proximal to the take-off of the anterior tibial artery. The politeal artery was selected not only because it is a location that is often occluded by plaque, but 
also because its relatively constant diameter and straight length make it a candidate for an idealized simulation such as that presented here.

The resting gradient was recorded. A blood pressure cuff was positioned at the calf level and inflated for 1 minute at $10 \mathrm{mmHg}$ above the systolic blood pressure. After cuff deflation, the hyperemic gradient was recorded. At that time, an IVUS catheter (Volcano Corporation) was passed across the lesion. The reference vessel diameter was measured in the normal arterial segment just proximal to the lesion. The minimal luminal area was measured at the narrowest point inside the lesion. Once the procedure was completed, the pressure wire was repositioned in the same segment of the popliteal artery, and measurements were repeated. Case files were collected and archived on the ComboMap console from Volcano Corporation.

An image of the situation is shown in Figure 1. The figure shows a close-up view of a plaque lesion which protrudes into a circular artery. The top image shows the idealized lesion prior to treatment and the bottom image is after treatment. It is seen that the lumen of the artery is enlargened by the treatment as confirmed by ultrasound. The lengths of the lesion will be systematically changed from $3 \mathrm{~mm}$ to $18 \mathrm{~mm}$ in the simulations to quantify the effect of length on the pressure drop through the lesion.

Numerical simulations of blood flow through the artery will be completed and the pressure drop through the lesion is calculated. Comparisons of steady flow with unsteady pulsatile flow will be made as will a comparison between the calculated and experimental results.

It is recognized that this plaque scenario is idealized in its axisymmetry and its shape. However idealization of the shape will allow generalized conclusions to be made which characterize the flow phenomena. Those generalizations can be extended to patient-specific situations in future work.

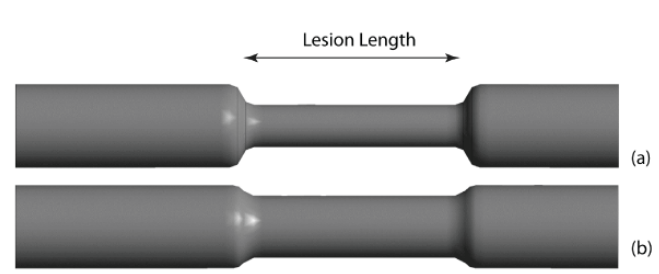

Figure 1: Artery segments with lesion (a) before treatment and (b) after treatment.

\section{Numerical model}

The numerical model is based on the control-volume calculation technique wherein the fluid domain is subdivided into a large multitude of control volumes. Equations of mass and momentum conservation are applied to each control volume (Equations $1 \& 2$ ). To make the present results most useful, both steady and unsteady calculations will be made. The steady calculations are made solely for the systolic peak velocity whereas the unsteady calculations are made for four cycles of the pulsating flow so that periodic steady flow is obtained.

Flow measurements made before and after treatment allowed the construction of the velocity waveforms which were applied at the inlet to the fluid domain. The flow profile at the inlet was fully developed and the upstream extension was sufficient that the results were not dependent on its length.

At the downstream location, zero second derivatives were employed on all transported variables. As with the inlet, the downstream extension was sufficiently long so that the results did not depend on its location.

The velocities recorded upstream of the lesion are displayed for one cardiac cycle in Figures 2 and 3.

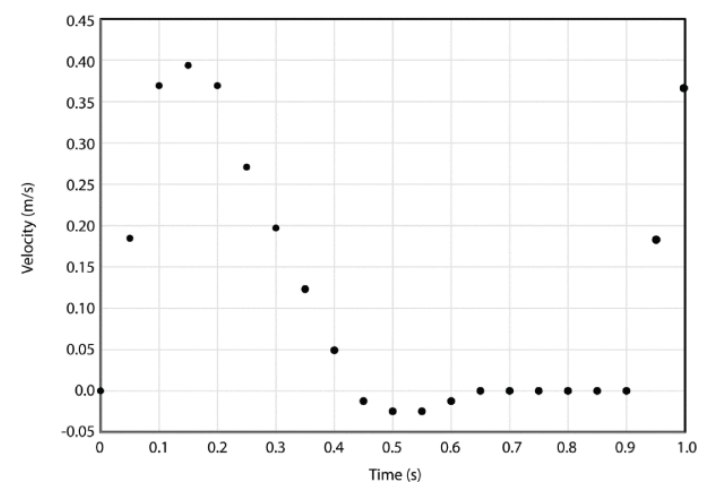

Figure 2: Single-cardiac cycle velocity recorded upstream of the lesion, pre-treatment. The single cardiac cycle ends at 0.9 seconds, the data is extended slightly to 1.0 seconds.

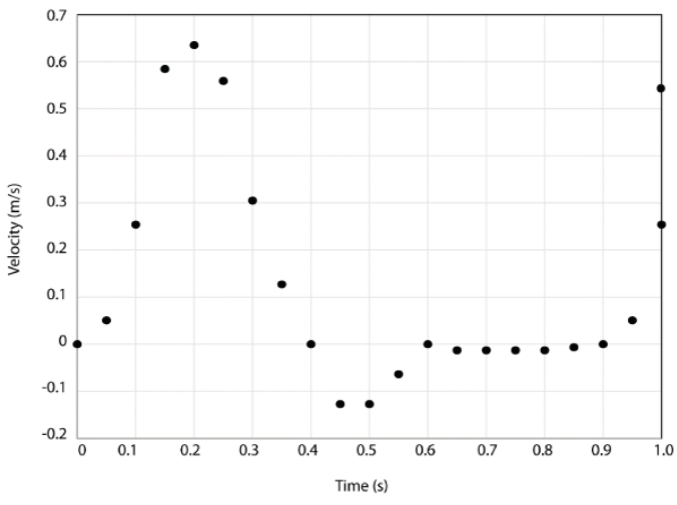

Figure 3: Single-cardiac cycle velocity recorded upstream of the lesion, post-treatment. The single cardiac cycle ends at 0.9 seconds, the data is extended slightly to 1.0 seconds.

The governing differential equations are:

$\frac{\partial u_{i}}{\partial x_{i}}=0$

for mass conservation and

$\rho \frac{\partial u_{j}}{\partial t}+\rho\left(u_{i} \frac{\partial u_{j}}{\partial x_{i}}\right)=-\frac{\partial p}{\partial x_{j}}+\frac{\partial}{\partial x_{i}}\left(\left(\mu+\mu_{t}\right) \frac{\partial u_{j}}{\partial x_{i}}\right) j=1,2,3$

for conservation of momentum. To simplify the expressions, tensor notation has been used. The symbols $\mathrm{u}, \rho, \mathrm{x}, \mathrm{p}$ and $\mu$ represent velocity, 
density, location, pressure, and viscosity, respectively. The subscript $\mathrm{t}$ refers to turbulent quantities.

To allow for the potential transition from laminar-to-turbulent flow, the shear stress transport model of Menter [46] is utilized which involves two turbulent transport equations for turbulent kinetic energy $\mathrm{k}$ and specific rate of turbulent dissipation $\omega$ (Equations $3 \& 4$ ).

$$
\frac{\partial(\rho k)}{\partial t}+\frac{\partial\left(\rho u_{i} k\right)}{\partial x_{i}}=\gamma P_{k}-\beta_{1} \rho k \omega+\frac{\partial}{\partial x_{i}}\left[\left(\mu+\frac{\mu_{t}}{\sigma_{k}}\right) \frac{\partial k}{\partial x_{i}}\right]
$$

and

$$
\begin{aligned}
& \frac{\partial(\rho \omega)}{\partial t}+\frac{\partial\left(\rho u_{i} \omega\right)}{\partial x_{i}}=\alpha \rho S^{2}-\beta_{2} \rho \omega^{2}+\frac{\partial}{\partial x_{i}}\left[\left(\mu+\frac{\mu_{t}}{\sigma_{\omega 1}}\right) \frac{\partial \omega}{\partial x_{i}}\right] \\
& +2\left(1-F_{1}\right) \rho \frac{1}{\sigma_{\omega 2} \omega} \frac{\partial k}{\partial x_{i}} \frac{\partial \omega}{\partial x_{i}}
\end{aligned}
$$

The symbol $\gamma$ is an intermittency term which takes on values of 0 when the flow is laminar and 1 when the flow is fully turbulent. Intermittency is solved from two connected transport equations (Equations 5 \& 6).

$$
\begin{aligned}
& \frac{\partial(\rho \gamma)}{\partial t}+\frac{\partial\left(\rho u_{i} \gamma\right)}{\partial x_{i}}=P_{\gamma, 1}-E_{\gamma, 1}+P_{\gamma, 2}-E_{\gamma, 2} \\
& +\frac{\partial}{\partial x_{i}}\left[\left(\mu+\frac{\mu_{t}}{\sigma_{\gamma}}\right) \frac{\partial \gamma}{\partial x_{i}}\right]
\end{aligned}
$$

and

$$
\frac{\partial(\rho \Pi)}{\partial t}+\frac{\partial\left(\rho u_{i} \Pi\right)}{\partial x_{i}}=P_{\Pi, t}+\frac{\partial}{\partial x_{i}}\left[\sigma_{\Pi, t}\left(\mu+\mu_{t}\right) \frac{\partial \Pi}{\partial x_{i}}\right]
$$

which are taken from Menter [47-49], but modified to account for internal flows. This method has been shown to correctly capture very low Reynolds numbers transitional flows in the literature [50-59].

The blood viscosity was modeled with a non-Newtonian model described in [9] as shown in Equation (7).

$$
\tau=K S^{n}
$$

where $\mathrm{K}=0.0147\left(\mathrm{~kg} / \mathrm{m}-\mathrm{s}^{1.22}\right), \mathrm{S}$ is the strain rate, and $\mathrm{n}=0.78$ [60].

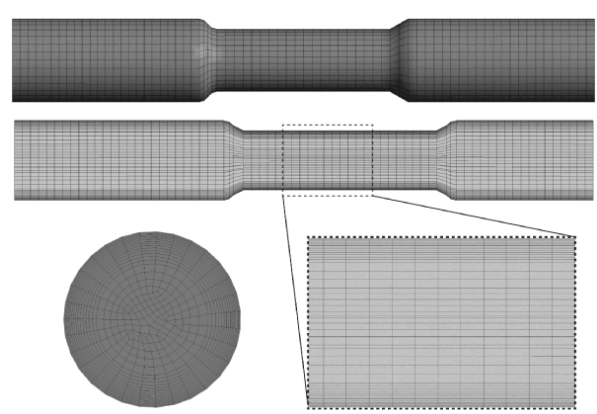

Figure 4: Side view, end view, and internal views of the computational mesh.

The spatial discretization was performed in a sequence of increasingly refined stages wherein the elements were reduced in size until the results were independent of mesh. The mesh was deployed finely near the artery wall where large gradients of velocity exist. A side view and end view of the mesh are shown in Figure 4.

The figure also shows an internal view of the mesh with a callout that magnifies the mesh across the stenosis lumen. The magnification shows the refinement of elements in the near wall region. The final number of elements depended on the length of the lesion but were approximately 50,000 .

Similarly, the time step size was modified until results were independent of time step. The final time step used for the calculations was 0.01 seconds. In total, three different calculations were made for each lesion. One calculation was for laminar flow at peak systolic velocity. The second calculation was pulsatile (four cardiac cycles) using a laminar solver, and the third calculation was pulsatile (four cardiac cycles) where laminar-to-turbulent transition was included. A comparison between these three calculations will be provided later and it will be seen that they are in good agreement with each other. Since it was found that the steady laminar simulation provided adequate flow/ pressure results, it is possible to save computational resources for future calculations.

\section{Results and Discussion}

The first set of results to be discussed is the pressure losses through the stenosis for the three calculation methods (steady laminar, unsteady laminar, and unsteady transitional). The comparison will be made at peak systole for the unsteady cases. Comparisons will be made both before and after the atherectomy treatment.

The plaque was removed through the use of the Diamondback 360 orbital atherectomy device (Cardiovascular Systems, Inc). We used a $2.0 \mathrm{~mm}$ crown which was initially activated at 60,000 rotation $/ \mathrm{min}$. After 2 passes, the orbital speed was increased to 90,000 rotations $/ \mathrm{min}$. The plaque removal procedure was terminated after the final 2 passes at 120,000 rotations $/ \mathrm{min}$. The activation time was 30 seconds per pass, with a pause of 30 seconds in between passes. The atherectomy result was checked via angiogram, and the residual stenosis was measured with the IVUS. Table 1 shows a summary of the results for the preoperative case. In the table, pressure drop through the lesion for the steady laminar, unsteady laminar, and unsteady transitional. The unsteady values were obtained at the systolic flow.

\begin{tabular}{|l|l|l|l|l|l|}
\hline Case & Pre/Post & $\begin{array}{l}\text { Lesion } \\
\text { Length } \\
(\mathbf{m m})\end{array}$ & $\begin{array}{l}\text { Steady } \\
\text { Laminar } \Delta \mathbf{P} \\
\text { (torr) }\end{array}$ & $\begin{array}{l}\text { Unsteady } \\
\text { Laminar } \Delta \mathbf{P} \\
\text { (torr) }\end{array}$ & $\begin{array}{l}\text { Unsteady } \\
\text { Transitional } \\
\Delta \mathbf{P} \text { (torr) }\end{array}$ \\
\hline 1 & Pre & 3 & 10.9 & 11.6 & 10.9 \\
\hline 2 & Pre & 6 & 11.3 & 12.0 & 11.3 \\
\hline 4 & Pre & 12 & 12.0 & 12.8 & 12.4 \\
\hline 5 & Pre & 18 & 12.8 & 13.9 & 13.1 \\
\hline
\end{tabular}

Table 1: Pre-treatment systolic pressure drop through lesion as a function of lesion length. 
Page 4 of 7

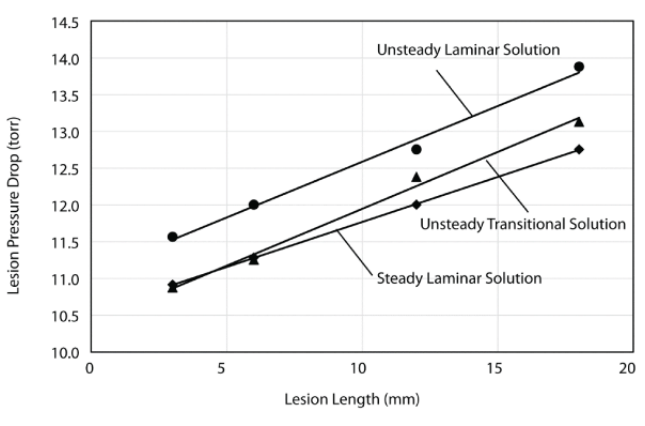

Figure 5: Pre-operation peak systolic pressure drop for unsteady laminar and unsteady transitional calculations. Circles, diamonds, and triangles correspond to unsteady laminar, steady laminar, and unsteady transitional flow, respectively.

In the clinical experiment, the lesion length was estimated to be 1 $\mathrm{cm}$ and the measured systolic pressure drop was 12 torr. This value agrees to within the accuracy of the measurements to the calculated results. The results of Table 1 are graphically displayed in Figure 5.

\begin{tabular}{|l|l|l|l|l|}
\hline Case & Pre/Post & $\begin{array}{l}\text { Lesion } \\
\text { Length } \\
(\mathbf{m m})\end{array}$ & $\begin{array}{l}\text { Unsteady } \\
\text { Laminar } \Delta \mathbf{P} \\
\text { (torr) }\end{array}$ & $\begin{array}{l}\text { Unsteady } \\
\text { Transitional } \Delta \mathbf{P} \\
\text { (torr) }\end{array}$ \\
\hline 1 & Pre & 3 & 2.26 & 2.11 \\
\hline 2 & Pre & 6 & 2.37 & 2.28 \\
\hline 4 & Pre & 12 & 2.93 & 2.81 \\
\hline 5 & Pre & 18 & 3.07 & 2.95 \\
\hline
\end{tabular}

Table 2: Pre-treatment mean pressure drop through lesion as a function of lesion length.

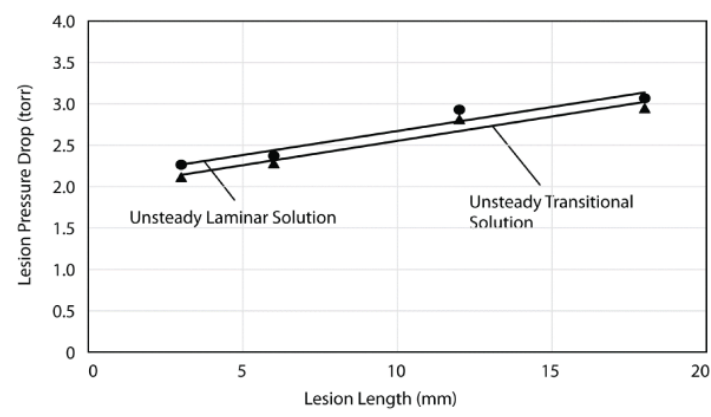

Figure 6: Pre-operation cardiac-cycle mean pressure drop for unsteady laminar and unsteady transitional calculations. Circles correspond to unsteady laminar calculations, triangles are for unsteady transitional calculations.

Similarly, Table 2 presents the cardiac-cycle average pressure drop through the lesion. The measured value for the $1 \mathrm{~cm}$ lesion was 2 torr, again, in good agreement with the calculations. The date from Table 2 is displayed graphically in Figure 6.
From Tables 1 and 2 and from Figures 5 and 6, it is seen that there is a slight difference between the three calculations methods (steady laminar, unsteady laminar, unsteady transitional) with the systolic pressure drop for the transitional calculation very closely matching that of the steady laminar case. The unsteady laminar situation slightly overpredicts the systolic pressure by less than $10 \%$. It is therefore open to question whether the added complexity of the transitional simulation is worthwhile.

For the cardiac-cycle averages listed in Table 2, again the unsteady laminar calculation slightly overpredicts the unsteady transitional by approximately $5 \%$. Again, this motivates the question of whether the complexity of transitional calculations is necessary for meaningful results.

Another conclusion from the results is that the length of the lesion does not dominate the pressure drop; despite a six-fold increase in the length of the lesion, there is approximately a $20 \%$ increase in systolic pressure drop and a $40 \%$ increase in cycle-average pressure drop. This issue will be explored in more detail later in this report but it indicates that the pressure drop caused by constriction (and flow acceleration) exceeds that caused by friction within the lesion. It is important to note that while flow acceleration results in a pressure decrease (Bernoulli Effect), it is possible for a pressure recovery to occur if the flow is decelerated carefully.

After the orbital atherectomy treatment, the pressure drop through the lesion is significantly reduced (even through the flowrate is increased by $61 \%$ at peak systolic flow and by $20 \%$ for the full cardiac cycle). Tabulated results are provided in Table 3. The pressure drop through the stenosis at systolic conditions is reduced by a factor of approximately 2.5 and the mean cardiac-cycle pressure is reduced by a factor of approximately 3.5 .

In the clinical experiment, the post-operative systolic pressure drop was measured to be 4 torr, again in agreement with the calculations.

\begin{tabular}{|l|l|l|l|l|l|}
\hline Case & Pre/Post & $\begin{array}{l}\text { Lesion } \\
\text { Length } \\
(\mathbf{m m})\end{array}$ & $\begin{array}{l}\text { Steady } \\
\text { Laminar } \\
\Delta \mathbf{P} \text { (torr) }\end{array}$ & $\begin{array}{l}\text { Unsteady } \\
\text { Laminar } \Delta \mathbf{P} \\
\text { (torr) }\end{array}$ & $\begin{array}{l}\text { Unsteady } \\
\text { Transitional } \\
\Delta \mathbf{P} \text { (torr) }\end{array}$ \\
\hline 6 & Post & 3 & 3.92 & 4.12 & 3.81 \\
\hline 7 & Post & 6 & 4.16 & 4.43 & 4.19 \\
\hline 8 & Post & 12 & 5.30 & 5.87 & 5.59 \\
\hline 9 & Post & 18 & 6.00 & 6.15 & 5.84 \\
\hline
\end{tabular}

Table 3: Post-treatment systolic pressure drop through lesion as a function of lesion length.

\begin{tabular}{|l|l|l|l|l|}
\hline Case & Pre/Post & $\begin{array}{l}\text { Lesion } \\
\text { Length } \\
(\mathbf{m m})\end{array}$ & $\begin{array}{l}\text { Unsteady } \\
\text { Laminar } \Delta \mathbf{P} \text { (torr) }\end{array}$ & $\begin{array}{l}\text { Unsteady Transitional } \\
\Delta \mathbf{P} \text { (torr) }\end{array}$ \\
\hline 6 & Post & 3 & 0.63 & 0.58 \\
\hline 7 & Post & 6 & 0.67 & 0.61 \\
\hline 8 & Post & 12 & 0.88 & 0.83 \\
\hline 9 & Post & 18 & 0.90 & 0.86 \\
\hline
\end{tabular}

Table 4: Post-treatment mean pressure drop through lesion as a function of lesion length. 
The results of Tables 3 and 4 are displayed graphically in Figures 7 and 8. It is again seen that there is good agreement between the three calculation methods and transitional calculations are not necessary for such calculations.

It is also seen that the impact of lesion length on pressure drop is not very large, a six-fold change in the lesion length changes the systolic and mean pressure drop by approximately $50 \%$. This finding again indicates that the pressure drop caused by constriction (and flow acceleration without downstream recovery) exceeds that caused by friction within the lesion.

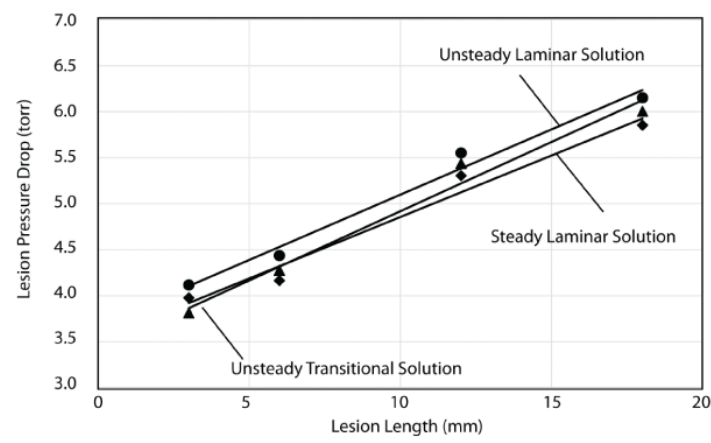

Figure 7: Post operation, peak systolic pressure drop for unsteady laminar and unsteady transitional calculations. Circles, diameters, and triangles correspond to unsteady laminar, steady laminar, and unsteady transitional flow, respectively.

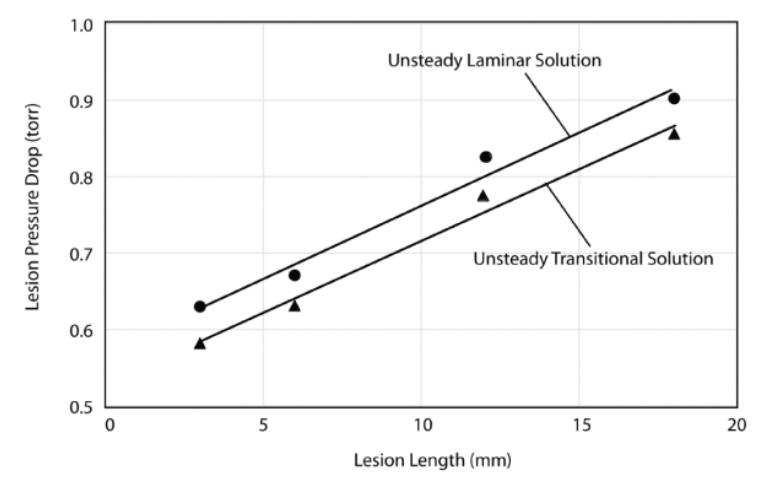

Figure 8: Post-operation cardiac-cycle mean pressure drop for unsteady laminar and unsteady transitional calculations. Circles correspond to unsteady laminar calculations; triangles are for unsteady transitional calculations.

To explore more fully the pressure variations within a lesion, two representative images have been prepared. The first, Figure 9, shows velocity contours along a central plane which bisects the lumen. In the figure, significant flow acceleration occurs at the entrance to the lesion. A strong jet emerges from the downstream end before spreading out to fill the cross section.

The acceleration causes a concomitant pressure loss (as expected from fluid mechanics) and the pressure drop is seen confined to the lesion entrance. The lack of a controlled downstream deceleration renders this pressure decrease permanent. There is a further decrease in pressure through the lesion but it is small compared to that at the lesion entrance. The lesion shown in Figures 9 and 10 was preoperative but it is representative of the fluid flow behavior for the other cases. This finding leads to the conclusion that the dominating factor to lesion pressure drop is the degree of acceleration (and consequently the decrease in pressure) rather than friction.

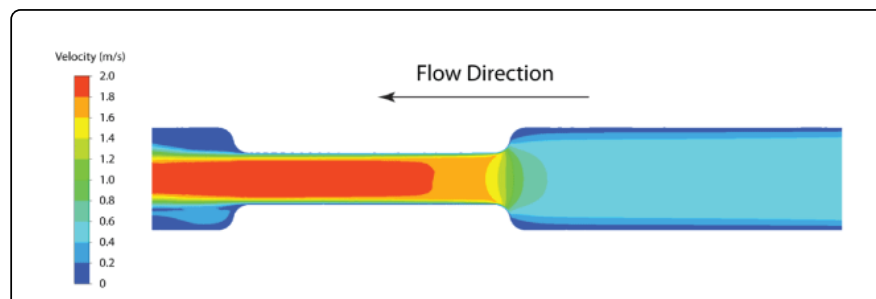

Figure 9: Velocity contour along a bisecting plane.

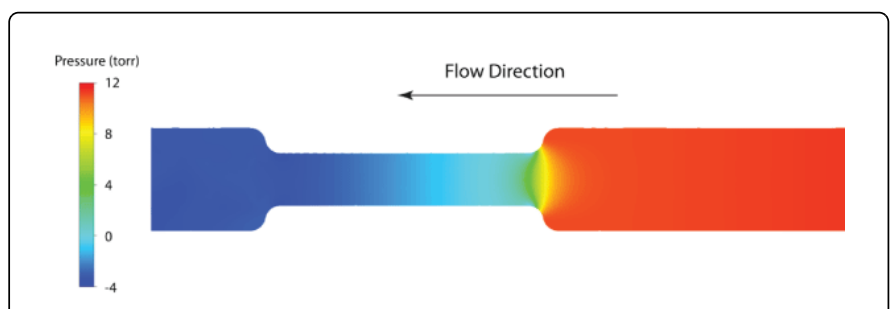

Figure 10: Pressure contour along a bisecting plane.

\section{Concluding remarks}

A numerical simulation has been performed to assess the impact of plaque removal on blood flow and pressure loss. Plaque removal was performed using an orbital atherectomy procedure on calcified plaque. Changes to the open cross section were measured by intravenous ultrasound and were used to construct an idealized computational model. It was found that the removal of plaque increased the flowrate through the stenosis while simultaneously decreasing the pressure drop. The peak systolic pressure drop decreased by a factor of 2.5 and the cycle-mean pressure decreased by a factor of 3.5. The results are consistent for lengths of plaque lesions that varied from $3 \mathrm{~mm}$ to 18 $\mathrm{mm}$; the impact of lesion length on pressure drop was much smaller than the impact of plaque thickness.

An exploration of velocity and pressure variation throughout the interior space revealed that the major component of pressure drop was from the blood flow acceleration at the stenosis inlet and the lack of a pressure recovery with deceleration. Only secondarily did friction within the lesion contribute to pressure variations.

The calculations were performed using three different numerical schemes of increasing complexity. The first was a steady laminar flow calculation at systolic conditions. The second was an unsteady laminar flow of four cardiac cycles to ensure that periodic steady conditions were reached. The final calculation approach utilized a new and complex transitional modeling code that accounts for laminar-toturbulent fluctuations. All methods were in good agreement so that it is not necessary to use more computational expensive methods.

Comparisons between the simulations and experiments were made and found to be in very good agreement both before and after the operation. This agreement lends to the veracity of the calculations. 
The next stages of the work involve obtaining patient-specific plaque profiles and repeating the calculations to determine whether the generalized findings presented here can also be applied to individual patients. It is also of interest how these results complement other works which show, for instance, effects of heart rate and the evolution of arterial disease and cardiac health [61,62]. This connection is only recently explored.

\section{Acknowledgements}

The authors gratefully acknowledge the support of Cardiovascular Systems Inc.

\section{References}

1. Ku DN (1997) Blood flow in arteries. Ann Rev Fluid Mech 29: 399-434.

2. Stehbens WE, Davis PF, Martin BJ (1990) Blood flow in large arteries: applications to atherogenesis and clinical medicine. Monograph Atheroscler. Basel, Karger 15: 1-15.

3. Sabbah HN, Khaja F, Brymer JF, Hawkins ET, Stein PD (1990) Blood flow in the coronary arteries of man: relation to atherosclerosis. Monogr Atheroscler 15: 77-90.

4. Friedman MH1, Bargeron CB, Mark FF (1990) Variability of geometry, hemodynamics and intimal response of human arteries. Monogr Atheroscler 15: 109-116.

5. Neofytou P, Drikakis D (2003) Non-Newtonian flow instability in a channel with a sudden expansion. J Non-Newtonian Fluid Mech 111: 127-150.

6. LaDisa J, Guler I, Olson L, Hetterick D, Kersten J, et al. (2003) Threedimensional computational fluid dynamics modeling of alterations in coronary wall shear stress produced by stent implantation. Ann Biomed Eng 31: 972-980.

7. Grigioni M, Daniele C, Morbiducci U, Del Gaudio C, D'Avenio G, et al (2005) A mathematical description of blood spiral flow in vessels: application to a numerical study of flow in arterial bending. J Biomech 38: 1375-1386.

8. Abraham JP, Sparrow EM, Lovik RD, (2008a) Unsteady, three dimensional fluid mechanic analysis of blood flow in plaque-narrowed and plaque-free arteries. Int J Heat Mass Transfer 51: 5633-5641.

9. Naughton NM, Plourde BD, Stark JR, Hodis S, Abraham JP (2014) Impacts of waveforms on the fluid flow, wall shear stress, and flow distribution in cerebral aneurysms and the development of a universal reduced pressure. J Biomed Sci and Eng 7: 7-14.

10. Gebreegziabher T, Sparrow EM, Abraham JP, Ayorinde E, Singh T (2011) High-frequency pulsatile pipe flows encompassing all flow regimes. Num Heat Transfer A 60: 811-826.

11. Gijsen FJ, van de Vosse FN, Janssen JD (1999) The influence of the nonNewtonian properties of blood on the flow in large arteries: steady flow in a carotid bifurcation model. J Biomech 32: 601-608.

12. Cho Y, Kensey K (1991) Effects of the non-Newtonian viscosity of blood on flows in a diseased arterial vessel. Part 1: Steady flows. Biorheology 28: 241-261.

13. Johnston BM, Johnston PR, Corney S, Kilpatrick D (2004) NonNewtonian blood flow in human right coronary arteries: steady state simulations. J Biomech 37: 709-720.

14. Khaled ARA, Vafai K (2003) The role of porous media in modeling flow and heat transfer in biological tissues. Int J Heat Mass Transfer 46: 4989-5003.

15. Khanafer K, Vafai, K (2006) The role of porous media in biomedical engineering as related to magnetic resonance imaging and drug delivery. Heat Mass Transfer 42: 939-953.

16. Khakpour M, Vafai, K (2008) A critical assessment of arterial transport models. Int J Heat Mass Transfer 51: 807-822.
17. Abraham JP, Sparrow EM, Gorman JM, Stark JR, Kohler RE (2013) A mass transfer model of temporal drug deposition in artery walls. Int. J. Heat Mass Transfer 59: 632-638.

18. Abraham JP, Stark JR, Gorman, JM, Sparrow EM, Kohler RE (2013) A model of drug deposition within artery walls. J Medical Devices 6: 020902

19. Stark JR, Gorman JM, Sparrow EM, Abraham JP, Kohler RE (2013), Controlling the rate of penetration of a therapuetic drug into the wall of an artery by means of a pressurized balloon. J Biomech Sci Eng 6: 527-532.

20. Wang S, Vafai K (2015) Analysis of Low Density Lipoprotein (LDL) Transport Within a Curved Artery. Ann Biomed Eng 43: 1571-1584.

21. Ellahi R, Rahman S, Nadeem U, Vafai K (2015) The blood flow of Prandtl fluid through a tapered stenosed arteries in permeable walls with magnetic field. Comm Theo Phys 63: 353-358.

22. O'Rourke MF, Staessen JA, Vlachopoulos C, Duprez D, Plante GE (2002) Clinical applications of arterial stiffness; definitions and reference values. Am J Hypertens 15: 426-444.

23. Pannier BM, Avolio AP, Hoeks A, Mancia G, Takazawa K (2002) Methods and devices for measuring arterial compliance in humans. Am J Hypertens 15: 743-753.

24. Baird RN, Bird DR, Clifford PC, Lusby RJ, Skidmore R, et al. (1980) Upstream stenosis. Its diagnosis by Doppler signals from the femoral artery. Arch Surg 115: 1316-1322.

25. Tang D, Yang C, Huang Y, Ku DN (1999) Wall stress and strain analysis using a three-dimensional thick-wall model with fluid-structure interactions for blood flow in carotid arteries with stenosis. Computers and Structures 72: 341-356.

26. Tang D, Yang C, Huang Y, Ku DN (1999) A 3-D thin-wall model with fluid-structure interactions for blood flow in carotid arteries with symmetric and asymmetric stenosis. Computers and Structures 72: 357-377.

27. Tang D, Yang C, Walker H, Kobayashi S, Ku DN (2002) Simulating cyclic artery compression using a 3D unsteady model with fluid-structure interactions. Computers and Structures 80: 1651-1665.

28. Tang D, Yang C, Kobayashi S, Zheng J, Vito RP (2003) Effect of stenosis asymmetry on blood flow and artery compression: A three-dimensional fluid-structure interaction model. Ann Biomed Eng 31: 1182-1193.

29. Tang D, Yang C, Kobayashi S, Ku DN (2004) Effect of a lipid pool on stress/strain distributions in stenotic arteries: 3-D fluid-structure interactions (FSI) models. J Biomech Eng 126: 363-370.

30. Zhao SZ, Xu XY, Hughes AD, Thom SA, Stanton AV, et al. (2000) Blood flow and vessel mechanics in a physiologically realistic model of a human carotid arterial bifurcation. J Biomech 33: 975-984.

31. Li Z, Kleinstreuer C (2005) Blood flow and structure interactions in a stented abdominal aortic aneurysm model. Med Eng Phys 27: 369-382.

32. Torii R, Oshima M, Kobayashi T, Takagi K, Tezduyar TE (2006) Fluidstructure interaction modeling of aneurysmal conditions with high and normal blood pressures. Computational Mechanics 38: 482-490.

33. Valencia A, Villanueva M (2006) Unsteady flow and mass transfer in models of stenotic arteries considering fluid-structure interaction. Int Comm Heat Mass Transfer 33: 966-975.

34. Torii R, Oshima M, Kobayashi T, Takagi K, Tezduyar TE (2007) Influence of wall elasticity in patient specific hemodynamic simulations. Computers and Fluids 36: 160-168.

35. Bluestein D, Alemu Y, Avrahami I, Gharib M, Dumont K, et al. (2008) Influence of microcalcifications on vulnerable plaque mechanics using FSI modeling. J Biomech 41: 1111-1118.

36. Janela J, Moura A, Sequeira A (2010) A 3D non-Newtonian fluidstructure interaction model for blood flow in arteries. J Comput Appl Mech 234: 2783-2791.

37. Kung EO, Les AS, Figueroa CA, Medina F, Arcaute K, et al. (2011) In vitro validation of finite element analysis of blood flow in deformable models. Ann Biomed Eng 39: 1947-1960. 
Citation: Plourde BD, Vallez LJ, Sun B, Abraham JP, Staniloe CS (2015) The Effect of Plaque Removal on Pressure Drop and Flow Rate through an Idealized Stenotic Lesion. Biol Med (Aligarh) 8: 261. doi: 10.4172/0974-8369.1000261

Page 7 of 7

38. Crosetto P, Reymond P, Deparis S, Kontaxakis D, Stergiopulos N, Quarteroni A (2011) A fluid-structure interaction simulation of aortic blood flow. Computers and Fluids 43: 46-57.

39. Malve M, Garcia A, Ohayon J, Martinez MA, (2012) Unsteady blood flow and mass transfer of a human left coronary artery bifurcation: FSI vs. CFD. Int Comm Heat Mass Transfer 39: 745-751.

40. Reymond P, Crosetto P, Deparis S, Quarteroni A, Stergiopulos N (2013) Physiological simulation of blood flow in the aorta: comparison of hemodynamic indices as predicted by 3-D FSI, 3-D rigid wall and 1-D models. Med Eng Phys 35: 784-791.

41. Staniloae CS, Korabathina R (2014) Orbital atherectomy: device evolution and clinical data. J Invasive Cardiol 26: 215-219.

42. Sun B, Vallez LJ, Plourde BD, Stark JR, Abraham JP (2015) Influence of supporting tissue on the deformation and compliance of healthy and diseased arteries. J Biomedical Science and Engineering 8: 490-499.

43. Helgeson ZL, Jenkins JS, Abraham JP, Sparrow EM (2011) Particle Trajectories and Agglomeration/Accumulation in Branching Arteries subjected to Orbital Atherectomy. Open Biomed Eng J 5: 25-38.

44. Ramazani-Rend R, Chelikani S, Sparrow EM, Abraham JP (2010) Experimental and numerical investigation of orbital atherectomy: Absence of cavitation. J Biomedical Science and Eng 3: 108-1116.

45. Adams GL, Khanna PK, Staniloae CS, Abraham JP, Sparrow EM (2011) Optimal techniques with the Diamondback $360^{\circ}$ System achieve effective results for the treatment of peripheral arterial disease. J Cardiovasc Trans Res 4: 220-229.

46. Menter FR (1994) Two-equation eddy-viscosity turbulence models for engineering applications. AIAA J32: 1598-1605.

47. Menter FR, Esch T, Kubacki S (2002) Transition modeling based on loca variables. 5th int. symposium on engineering turbulence modeling and measurements, Mallorca. Spain 2002.

48. Menter FR Langtry R, Likki R, Suzen Y, Huang P, Volker S (2004) A correlation-based transition model using local variables, Part I - model formulation. Proceedings of ASME Turbo Expo Power for Land, Sea, and Air, Vienna, Austria, June 14-17, 2004.

49. Menter FR Langtry R, Likki R, Suzen Y, Huang P, Volker S (2004), A correlation-based transition model using local variables, Part II - test cases and industrial applications. Proceedings of ASME Turbo Expo Power for Land, Sea, and Air, Vienna, Austria, June 14-17, 2004.

50. Abraham JP, Tong JCK, Sparrow EM (2008) Prediction of laminarturbulent transition and friction factors in transitional flows. ASME
International Congress and Expo. Boston, MA, October 31 - November 5,2008 .

51. Abraham JP, Tong JCK, Sparrow EM (2008) Breakdown of laminar pipe flow into transitional intermittency and subsequent attainment of fully developed intermittent or turbulent flow. Num Heat Transfer B 54: 103-115.

52. Sparrow EM, Tong JCK, Abraham JP (2008) Fluid flow in a system with separate laminar and turbulent zones. Num Heat Transfer A 53: 341-353.

53. Sparrow EM, Abraham JP, Minkowycz WJ (2009) Flow separation in a diverging conical duct: Effect of Reynolds number and divergence angle. Int J Heat Mass Transfer 52: 3079-3083.

54. Abraham JP, Sparrow EM, Tong JCK (2009) Heat transfer in all pipe flow regimes - laminar, transitional/intermittent, and turbulent. Int J Heat Mass Transfer 52: 557-563.

55. Minkowycz WJ, Abraham JP, Sparrow EM (2009) Numerical simulation of laminar breakdown and subsequent intermittent and turbulent flow in parallel plate channels: Effects of inlet velocity profile and turbulence intensity. Int J Heat Mass Transfer 52: 4040-4046.

56. Lovik RD, Abraham JP, Sparrow EM (2009) Pulsating fluid flows undergoing transitions between laminar, transitional, and turbulent regimes. ASME 2009 Summer Bioengineering Conference, Lake Tahoe, CA, June 17-21.

57. Lovik RD, Abraham JP, Minkowycz WJ, Sparrow EM (2009) Laminarization and turbulentization in a pulsatile pipe flow. Num Heat Transfer Part A 56: 861-879.

58. Abraham JP, Sparrow EM, Tong JCK, Bettenhausen DW (2010) Internal flows which transist from turbulent through intermittent to laminar. Int J Thermal Sciences 49: 256-263.

59. Abraham JP, Sparrow EM, Minkowycz WJ (2011) Internal-flow nusselt numbers for the low-reynolds-number end of the laminar-to-turbulent transition regime. Int J Heat Mass Transfer 54: 584-588.

60. Walburn FJ, Schneck DJ (1976) A constitutive equation for whole human blood. Biorheology 13: 201-210.

61. Scicchitano P, Cortese F, Ricci G, Carbonara S, et al. (2014) Ivabradine, coronary artery disease, and heart failure: Beyond rhythm control. Drug Design, Development and Therapy 8: 689-700.

62. Scicchitano P, Carbonara S, Ricci G, Mandurino C, Locorotondo M, et al. (2012) HCN channels and heart rate. Molecules 17: 4225-4235. 